\title{
Application of Chitosan Based Coating in Fruit and Vegetable Preservation: A Review
}

\section{Duan Jianglian and Zhang Shaoying*}

College of Engineering, Shanxi Normal University, Linfen 041004, China

\begin{abstract}
Edible coating is beneficial to the shelf life of postharvest fruit and vegetable. Chitosan-based coating was concerned in recent years owing to its non-toxic, biodegradable, and biocompatible properties. In view of the deficiency of single chitosan coating, there are two main methods to improve the property of chitosan-based coating at present. One method is that the chitosan were combined with organic compounds, inorganic compound, or biological control agents. The other method is that single chitosan coating was applied with non-coating remedies including heat treatment, hypobaric treatment, gas fumigation, and modified atmosphere packaging. After applying improved chitosan-based coating, the preserving effects were increased in most of the cases compared with single chitosan coating.
\end{abstract}

Keywords: Chitosan; Coating; Fruit; Vegetable; Preservation

\section{Introduction}

Postharvest fruit and vegetable are living organisms, undertaking metabolism ceaselessly. Their character such as nutrition, favor, and appearance deteriorated during the process of storage and transportation owing to water loss, browning, decay, and so on $[1,2]$. Thus, the commercial value also decreases and many damages are caused to producer. To extend the shelf life of postharvest fruit and vegetable, some effective measures including low temperature, modified atmosphere packaging, irradiation and coating, have been applied [35]. In those measures, edible coating is one of promising methods because of its particular properties, which could avoid moisture loss and aromas loss, and inhibit the oxygen penetration to the plant tissue or microbial growth. In addition, edible coating is convenient and conforms to food safety [6]. Many materials such as polysaccharides, proteins, essential oils, may economically serve as edible coatings [7-9].

Chitosan is a linear polysaccharide consisting of $\beta$ - $(1 \rightarrow 4)$-linked 2-amino-2- deoxy-D-glucose residues, originating from deacetylated derivative of chitin, which is the second most abundant polysaccharide in nature after cellulose. It was non-toxic, biodegradable, biofunctional, and biocompatible. Chitosan has strong antimicrobial and antifungal activities that could effectively control fruit decay [10]. It could easily form coating on fruit and vegetable, and the respiration rate of fruit and vegetable was reduced by adjusting the permeability of carbon dioxide and oxygen [11]. Considering the superior properties of chitosan, it has been successfully used in many postharvest fruits and vegetables, such as grape, berry, jujube and fresh-cut lotus root [9,1214]. Though chitosan coating has many advantages to the preservation of postharvest fruit and vegetable, as for specific fruit or vegetable, single chitosan coating sometimes demonstrates a certain defect, which includes limited inhibition to especial microorganism that leads fruit to decay, and poor coating structure to adjust the permeability of carbon dioxide and oxygen [15]. To effectively apply the chitosan coating, the chitosan was combined with other substances. In addition, the single chitosan coating was often combined with physical methods such as short heating, short gas fumigation, modified atmosphere packaging, and so on $[3,5,16]$.

This review attempts to summarize the general development of various chitosan-based coatings, based on the current situation of research and progress in the preservation of fruit and vegetable. We expect that this review will provide insights for researchers working in postharvest preservation.

\section{Chitosan Based Composite Coating}

\section{Composite coating of chitosan and organic compounds}

Chitosan combined with essential oil: Essential oils are natural antioxidant and antimicrobial lipidic substances extracted from plants. Most of them consist of a mixture of terpens, terpenoids and other aromatic and aliphatic constituents [17]. They are gaining increasing interest because of relatively safe status, wide acceptance by consumers, and exploitation for potential multi-purpose functional uses. Filmforming dispersions (FFD) were prepared with $1 \%$ high molecular weight chitosan and $3 \%$ lemon essential oil. Chitosan coatings did not show a significant effect in terms of the acidity, $\mathrm{pH}$ and soluble solid content of strawberries throughout storage. In contrast, coatings slowed down the respiration rate of samples when lemon essential oil was added to the FFD. Adding lemon essential oil enhanced the chitosan antifungal activity both in vitro tests and during cold storage in strawberries inoculated with a spore suspension of Botrytis cinerea [12].

Chitosan combined with organic acid: Organic acids are weak acids and do not dissociate completely in water, whereas the strong mineral acids do. Contrary to the use of mineral acids, organic acids are easy to handle, non-corrosive in nature, biodegradable and cause no harm to the coated fruit and vegetable. They have been used as substitutes for sulfite to prevent enzymatic browning, alone or in combination with antimicrobial agent [18]. The effect of chitosan

*Corresponding author: Zhang Shaoying, College of Engineering, Shanx Normal University, Linfen 041004, China, Tel: +86 357 2051247; E-mail: zsynew@163.com

Received February 14, 2013; Accepted April 10, 2013; Published April 15, 2013

Citation: Jianglian D, Shaoying Z (2013) Application of Chitosan Based Coating in Fruit and Vegetable Preservation: A Review. J Food Process Technol 4: 227. doi:10.4172/2157-7110.1000227

Copyright: (C) 2013 Jianglian D, et al. This is an open-access article distributed under the terms of the Creative Commons Attribution License, which permits unrestricted use, distribution, and reproduction in any medium, provided the original author and source are credited. 
coating combined with phytic acid on the preservation of fresh cut lotus root was investigated. The result showed that composite coating with $1 \%$ chitosan and $1 \%$ phytic acid could decrease the weight loss rate and malondialdehyde (MDA) content of fresh-cutting lotus root, postpone browning, restrain the activities of peroxidase (POD), polyphenol oxidase (PPO) and phenylalanine ammonia-lysae (PAL), and maintain the content of vitamin $\mathrm{C}$ and polyphenol at relatively high level. At day 8, the weight loss rate of coated fresh cut lotus root was one half of control, MDA content was $18.8 \%$ lower, and $\mathrm{L}$ value was $51.2 \%$ higher than that of control sample. Composite coating with chitosan combined phytic acid is an effective method to preserve fresh cut lotus root, superior to single chitosan coating [19]. However, aciddissolved chitosan solutions develop bitterness and astringency tastes, making chitosan coated foods less practical on the real market [20].

Chitosan combined with other organic matters: Other organic matters such as ethanol, wax, and so on, could also improve the properties of chitosan coating in fruit preservation. Artificially inoculated single berries or clusters were immersed in chitosan, ethanol, or their mixture. The tests with small clusters were carried out to simulate commercial prolonged cold storage of table grapes. The combination of reduced doses of chitosan and ethanol improved the control of gray mold of table grapes compared to their application alone, and the effect was at least additive and at times synergistic [21].

\section{Composite coating of chitosan and inorganic compound}

Chitosan combined with metalions: Calcium ions perform multiple roles in plant cell physiology. They are important intracellular messengers, mediating responses to hormones, biotic and abiotic stress signals and a variety of developmental processes [22]. They also play an essential role in the structural maintenance of membranes and cell walls. Calcium ions cross-link free carboxyl groups on adjacent polygalacturonate chains present in the middle lamella of the plant cell wall contributing to cell-cell adhesion and cohesion. Preharvest and postharvest treatments with calcium salts have been effective in controlling several physiological disorders, reducing the incidence of fungal pathogens and maintaining fruit firmness [23]. Strawberries (Fragaria xananassa Duch.) were coated with chitosan combined with calcium gluconate. Following treatment, strawberries were stored at $10^{\circ} \mathrm{C}$ and $70 \pm 5 \% \mathrm{RH}$ for one week. No sign of fungal decay was observed during the storage period for fruit coated with $1.5 \%$ chitosan or $1 \%$ chitosan $+0.5 \%$ CaGlu. By contrast, $12.5 \%$ of the strawberries coated with $1 \%$ chitosan lacking calcium salt were infected after five days of storage. And addition of calcium to the chitosan solution increased the firmness and nutrients of the fruit [24]. In addition, zinc ion also attracted the interest of several researchers, because of its physiological functions. Zinc is one of the most important essential micro-metallic elements in the human body. It is an essential component of a number of important proteins and is indispensable for its stability and catalytic functions [25]. Cerium ion has good antibiotic capability and cleavage of the phosphodiester [26]. The complex of zinc (II) and cerium (IV) with chitosan had been applied for preserving Chinese jujube fruits to expand their shelf life and decrease residues of organophosphorus pesticides on the fruits [27].

Chitosan combined with inorganic nano-material: Emerging at the end of the 1980s, nanotechnology is currently rapidly developing and being widely used in the material, chemical, and physical fields. Different from normal-sized substances, nano-sized substances show quanta size, small size, surface, and macroscopic quanta size effects [28]. At present, nano- $\mathrm{ZnO}$, nano-silicon and nano- $\mathrm{CaCO}_{3}$ were used in postharvest fruit preservation. The effect of $1 \%$ chitosan film with
$0.04 \%$ nano-silicon dioxide on the qualitative properties of harvested jujube under ambient temperature was investigated. After 32 day, the red index, decay incidence, weight loss, and respiration rate of the coated jujubes were lower compared with those of the control. The lower PAL activity and higher activities of scavenger antioxidant enzymes (i.e., SOD, POD, and CAT) of the coated jujubes can be attributed to the compound coating. Increased MDA in the coated jujubes was restrained. Composite coating had shown to be superior in preserving total flavonoid than chitosan coating alone. But no differences were observed in terms of vitamin C loss and total polyphenol content between composite coating and control $[13,29,30]$.

\section{Composite coating of chitosan and biological control agents}

Biological control with antagonistic microorganisms has been considered the most promising alternative method for inhibition of postharvest diseases in recent years, especially for control of woundinvading pathogens [31]. At present there are several commercial products available in the market for postharvest use, such as Biosave (Pseudomonas syringae) registered in the USA and "Shemer" (Metschnikowia fructicola) registered in Israel [32]. The application of L. enzymogenes 3.1T8 in combination with chitosan reduced the number of diseased plants by $50-100 \%$ in four independent experiments relative to the Pythium control of preserved cucumber. However, application of chitosan or the bacterial inoculant alone was not effective [33].

\section{Chitosan Coating Combined With Non-Coating Treatment}

\section{Integrated application of chitosan coating and heat treatment}

Heat treatment is an effective non-chemical method for controlling postharvest pests and diseases if suitable combinations of temperatures and exposure times are selected to prevent quality loss. The use of a combination of such techniques in the postharvest handling of fresh products is increasing [34]. Apples (Malus domestica Borkh. cv. Gala) were heat-treated at $38^{\circ} \mathrm{C}$ for 4 days (heat treatment) before or after coated with $1 \%$ chitosan. Following treatment, apples were stored at $0^{\circ} \mathrm{C}$ for 8 weeks and $20^{\circ} \mathrm{C}$ for 7 days as shelf life. The heat treatment + chitosan treated fruit showed the lowest respiration rate, ethylene evolution, malondialdehyde and membrane leakage, and the highest firmness and consumer acceptance among the treatments. At the same time, this combined treatment could inhibit the lost of green color, titratable acidity and weight loss compared with HT alone [16].

\section{Integrated application of chitosan coating and hypobaric treatment}

Among the physical means for controlling postharvest decay of fruit and vegetables, the use of sub-atmospheric pressure treatments has been largely unexploited to date. It has been reported that hypobaric treatments, applied during all or almost all of the storage period, delay the ripening of some climateric fruits. The effectiveness of chitosan and short hypobaric treatments to control storage decay of sweet cherries was investigated over 2 years. The results indicate that the combination of hypobaric and chitosan treatments is a valid strategy for increasing the effectiveness of the treatments in controlling postharvest decay of sweet cherries $[35,36]$.

\section{Integrated application of chitosan coating and gas fumigation}

1-methylcyclopropene (1-MCP), an inhibitor of ethylene action, acts at very low concentration for delaying fruit ripening and improving storage quality of many fruits and vegetables. It is nontoxic, 
odorless and highly effective and has also been commercially used to extend the storage life of horticultural products [37]. The combination of 1-MCP and chitosan coating could effectively improve the storage life extension and quality maintenance of Indian jujube fruit at room temperature storage [38]

\section{Integrated application of chitosan coating and modified atmosphere packaging}

Modified atmosphere packaging (MAP) is an important technique for modifying the in-package atmosphere using polymeric films with or without perforations to reduce quality deterioration and improve shelf-life of the packaged fruits and vegetables through water loss, metabolic and microbial activity reduction. Reuck et al found that the combination of chitosan $\left(1.0 \mathrm{~g} \mathrm{~L}^{-1}\right)+$ MAP (control) was effective in preventing decay, browning and retaining the pericarp color in the cultivar McLean's Red compared with single MAP. Chitosan (1.0 $\left.\mathrm{gL}^{-1}\right)+$ MAP significantly reduced PPO and POD activity, retained membrane integrity, anthocyanin content and prevented the decline of pericarp color values during storage [39].

\section{Conclusion}

To effectively extend the shelf life of postharvest fruit and vegetable, chitosan-based coating as a relatively convenient and safe measure, is more and more concerned in food industry in recent years. In view of the deficiency of single chitosan coating, there are two main methods to improve the property of chitosan coating. One method is that the chitosan were combined with organic compounds such as essential oil, organic acid, or inorganic compound including metal ions and inorganic nano-material, as well as biological control agents. The other method is that the single chitosan coating was applied with physical remedies containing heat treatment, hypobaric treatment, gas fumigation and modified atmosphere packaging. After applying improved chitosan-based coating, the preserving effects were increased in most of the cases compared with single chitosan coating.

\section{Acknowledgements}

This work was supported by project of the National Natural Science Foundation of China under grant no. 31101359, and was also supported by Program for the Innovative Talents of Higher Learning Institutions of Shanxi (2012).

\section{References}

1. Gatto MA, Ippolito A, Linsalata V, Cascarano NA, Nigro F, et al. (2011) Activity of extracts from wild edible herbs against postharvest fungal diseases of fruit and vegetables. Postharvest Biol Tec 61: 72-82.

2. Terry LA, Joyce DC (2004) Elicitors of induced disease resistance in postharvest horticultural crops: a brief review. Postharvest Biol Tec 32: 1-13.

3. Xanthopoulos G, Koronaki ED, Boudouvis AG (2012) Mass transport analysis in perforation-mediated modified atmosphere packaging of strawberries. J Food Eng 111: 326-335.

4. Castagna A, Chiavaro E, Dall'asta C, Rinaldi M, Galaverna G, et al. (2013) Effect of postharvest UV-B irradiation on nutraceutical quality and physical properties of tomato fruits. Food Chem 137: 151-158.

5. Sañudo MB, Siller-Cepeda J, Muy-Rangel D, Heredia JB (2009) Extending the shelf-life of bananas with 1-methylcyclopropene and a chitosan-based edible coating. J Sci Food Agr 89: 2343-2349.

6. Mantilla N, Castell-Perez ME, Gomes C, Moreira RG (2013) Multilayered antimicrobial edible coating and its effect on quality and shelf-life of fresh-cut pineapple (Ananas comosus). Food Sci Technol 51: 37-43.

7. Vanzela ESL, Nascimento PD, Fontes EAF, Mauro MA, Kimura M (2013) Edible coatings from native and modified starches retain carotenoids in pumpkin during drying. Food Sci Technol 50: 420-425.

8. Lima MA, Cerqueira MA, Souza BWS, Santos ECM, Teixeira JA, et al. (2010)
New edible coatings composed of galactomannans and collagen blends to improve the postharvest quality of fruits -Influence on fruits gas transfer rate. $J$ Food Eng 97: 101-109.

9. Santos NSD, Aguiar AJA, Oliveira CED, Sales CVD, Silva SDM, et al (2012) Efficacy of the application of a coating composed of chitosan and Origanum vulgare L. essential oil to control Rhizopus stolonifer and Aspergillus niger in grapes (Vitis labrusca L.). Food Microbiol 32: 345-353.

10. Aider M (2010) Chitosan application for active bio-based films production and potential in the food industry: Review. Food Sci Technol-LEB 43: 837-842.

11. Elsabee MZ, Abdou ES (2013) Chitosan based edible films and coatings: A review. Mater Sci Eng C Mater Biol Appl 33: 1819-1841.

12. Perdones A, Sánchez-González L, Chiralt A, Vargas M (2012) Effect of chitosan-lemon essential oil coatings on storage-keeping quality of strawberry. Postharvest Biol Tec 70: 32-41

13. Yu YW, Zhang SY, Ren YZ, Li H, Zhang XN, et al. (2012) Jujube preservation using chitosan film with nano-silicon dioxide. J Food Eng 113: 408-414.

14. Xing Y, Li X, Xu Q, Jiang YH, Yun J, et al. (2010) Effects of chitosan-based coating and modified atmosphere packaging (MAP) on browning and shelf life of fresh-cut lotus root (Nelumbo nucifera Gaerth). Innov Food Sci Emerg 11: 684-689.

15. Ravi KMNV (2000) A review of chitin and chitosan applications. React funct Polym 46: 1-27.

16. Shao XF, Tu K, Tu S, Tu J (2012) A Combination of Heat Treatment and Chitosan Coating Delays Ripening and Reduces Decay in "Gala" Apple Fruit. J Food Quality 35: 83-92

17. Bakkali F, Averbeck S, Averbeck D, Idaomar M (2008) Biological effects of essential oils--a review. Food Chem Toxicol 46: 446-475.

18. Qi HP, Hu WZ, Jiang A, Tian MX, Li YQ (2010) Extending shelf-life of Fresh-cut 'Fuji' apples with chitosan-coatings. Innov Food Sci Emerg 12: 62-66.

19. Yu YW, Li H, Jinhua D, Ren YZ (2012) Study of Natural Film with Chitosan Combining Phytic Acids on Preservation of Fresh-cutting Lotus Root. J Chinese Institute Food Sci Tech 12: 131-136.

20. Han C, Lederer C, McDaniel M, Zhao YY (2005) Sensory Evaluation of Fresh Strawberries (Fragaria ananassa) Coated with Chitosan-based Edible Coatings. J Food Sci 70: S172-S178.

21. Romanazzi G, Karabulut OA, Smilanick JL (2007) Combination of chitosan and ethanol to control postharvest gray mold of table grapes. Postharvest Biol Tec 45: $134-140$.

22. Reddy VS, Reddy AS (2004) Proteomics of calcium-signaling components in plants. Phytochemistry 65: 1745-1776.

23. Bakshi P, Masoodi FA, Chauhan GS, Shah TA (2005) Role of calcium in postharvest life of temperate fruits: A review. J Food Sci Tech Mys 42: 1-8.

24. Muñoz PH, Almenar E, Valle VD, Velez D, Gavar R (2008) Effect of chitosan coating combined with postharvest calcium treatment on strawberry (Fragaria $\times$ ananassa) quality during refrigerated storage. J Food Chem 110: 428 - 435.

25. Wagner CC, Baran EJ (2009) Vibrational spectra of $\mathrm{Zn}$ (II) complexes of the amino acids with hydrophobic residues. Spectrochim Acta A Mol Biomol Spectrosc 72: 936-940.

26. Huang LF, Xuesong S (2002) The Biological Function of Rare Earth Element Acta Medicinae Sinica 15: 693-695

27. Wu H, Wang D, Shi J, Xue S, Gao M (2010) Effect of the complex of zincl and ceriumIV with chitosan on the preservation quality and degradation of organophosphorus pesticides in Chinese jujube (Zizyphus jujuba Mill. cv. Dongzao). J Agric Food Chem 58: 5757-5762.

28. Hu GH, Hoppe S, Feng LF, Fonteix C (2007) Nano-scale phenomena and applications in polymer processing. Chem Eng Sci 62: 3528-3537.

29. Jiang M, Ye XL, Qiu Q (2012) Study on the preservation effect of chitosan and nano-ZnO compound coating on Shatang mandarin. Sci Tech Food Industry 33: $348-351$

30. Luo ZS, Xu XL, Xu TQ, Xie J (2009) Effect of chitosan coating with nano-CaCO3 appendix on quality of fresh cut yam. Transactions of the Chinese Society for Agricultural Machinery 40: 125-128. 
Citation: Jianglian D, Shaoying Z (2013) Application of Chitosan Based Coating in Fruit and Vegetable Preservation: A Review. J Food Process Technol 4: 227. doi:10.4172/2157-7110.1000227

Page 4 of 4

31. Janisiewicz WJ, Conway WS (2010) Combining biological control with physical and chemical treatments to control fruit decay after harvest. Stewart Postharvest Review 6: 1-16.

32. Droby S, Wisniewski M, Macarisin D, Wilson C (2009) Twenty years of postharvest biocontrol research: is it time for a new paradigm? Postharvest Biol Tec 52: 137-145

33. Postma J, Stevens LH, Wiegers GL, Davelaar E, Nijhuis EH (2009) Biological control of Pythium aphanidermatum in cucumber with a combined application of Lysobacter enzymogenes strain 3.1T8 and chitosan. Biol Control 48: 301-309.

34. Zhao Y, Tu K, Su J, Tu S, Hou Y, et al. (2009) Heat treatment in combination with antagonistic yeast reduces diseases and elicits the active defense responses in harvested cherry tomato fruit. J Agric Food Chem 57: 7565-7570.

35. Romanazzi G, Nigro F, Ippolito A, Salerno M (2001) Effect of short hypobaric treatments on postharvest rots of sweet cherries, strawberries and table grapes. Postharvest Biol Tec 22: 1-6.

36. Romanazzi G, Nigro F, Ippolito A (2003) Short hypobaric treatments potentiate the effect of chitosan in reducing storage decay of sweet cherries. Postharvest Biol Tec 29: 73-80.

37. Valero D, Romero DM, Valverde JM, Guilléna F,Seranno M (2003) Quality improvement and extension of shelf life by 1-methylcyclopropene in plum as affected by ripening stage at harvest. Innov Food Sci Emerg 4: 339-348.

38. Zhong QP, Xia WS (2007) Effect of 1-methylcyclopropene and/or chitosan coating treatments on storage life and quality maintenance of Indian jujube fruit. Food Sci Technol 40: 404-411.

39. Reuck KD, Sivakumar D, Korsten L (2009) Effect of integrated application of chitosan coating and modified atmosphere packaging on overall quality retention in litchi cultivars. J Sci Food Agr 89: 915-920. 